\title{
LETTER
}

\section{Peripherally inserted central catheters: a walk down memory lane ...}

\author{
Jack JM Ligtenberg*1 ${ }^{* 1}$ Mirjam Holman'1, Matijs van Meurs², Jan C ter Maaten ${ }^{1}$ and Jan G Zijlstra ${ }^{2}$ \\ See related research by Pittiruti et al., http://ccforum.com/content/16/1/R21/abstract
}

Central venous catheters (CVCs) are essential in the treatment of critically ill patients. For skilled intensive care unit (ICU) physicians, insertion of these catheters in large central veins is routine practice. Peripherally inserted central catheters (PICCs) were used in the early phase of intensive care as a surrogate for centrally inserted lines by less experienced physicians and in some departments (for example, hematology) with very specific patient categories. With the development of the ICU, peripherally inserted lines have been abandoned for more than two decades, at least in our center. Many bleeding and more serious local complications occurred. In more skilled hands, these lines were also not very popular, because of spasm of the vein, a tendency to take the wrong route (to the head), and thrombosis of the vein in up to $8 \%$ of patients [1].
In a study in the previous issue of Critical Care, Pittiruti and colleagues [2] evaluated 89 patients in whom ultrasound-guided insertion of multi-lumen CVCs in the deep veins of the upper mid arm (PICC) was performed. Besides 13 minor complications at insertion and two cases of symptomatic thrombosis (however, not routinely screened for), few complications occurred, and the authors conclude that PICC can be successfully used in most ICU patients. Before we advocate its routine use in the ICU, we need more and better studies. PICCs cannot compare with the historical experience with centrally inserted central catheters (CICCs). Skilled personnel, routine use of ultrasound, and insertion bundles have lowered the incidence of complications of CICCs. We would advocate a head-to-head comparison before we introduce PICC as more than a last resort.

\section{Authors' response}

Mauro Pittiruti and Giancarlo Scoppettuolo

Ligtenberg and colleagues are right when they point out that, two decades ago, PICCs were associated with exceedingly high rates of local complications, venous thrombosis, and malpositions. However, in this century, PICCs are a completely different type of device: they are made of highly biocompatible material, they are inserted in the deep veins of the arm by ultrasound, and their position is verified by real-time methods such as intracavitary electrocardiogram. Ultrasound-inserted PICCs are now used in most ICUs in the US and are known to carry a low risk of catheter-related bloodstream infections (CRBSIs) (in a recent ICU study [3], the rates of incidence of CRBSI were 2.2 per 1,000 catheter days in

\footnotetext{
*Correspondence: j.j.m.ligtenberg@umcg.nl

'Emergency Department, University Medical Center (UMCG), PO Box 30001,

9700 RB Groningen, The Netherlands

Full list of author information is available at the end of the article
}

PICCs and 6.0 in CVCs; in a case control study carried out in our hospital [4], a proper bundle of interventions decreased the incidence of CRBSI from 2.6 to 0), a low risk of venous thrombosis (in a recent prospective study of 2,014 PICCs, the incidence of venous thrombosis was $3 \%$ [5]; in a study of 1,307 PICCs, a proper insertion technique - that is, ultrasound guidance + real-time positioning of the tip + careful ultrasound evaluation of vein diameter - decreased the incidence of thrombosis to $1.4 \%[6]$ ), and - as shown by our paper [2] - no relevant insertion-related complications.

We are sure that Ligtenberg and colleagues would agree with our conclusions: there is enough evidence to support further prospective trials comparing the clinical outcome of PICCs versus CVCs in ICU patients.

\footnotetext{
Abbreviations

CICC, centrally inserted central catheter; CRBSI, catheter-related bloodstream infection; CVC, central venous catheter; ICU, intensive care unit; PICC, peripherally inserted central catheter.
} 


\section{Competing interests}

The authors declare that they have no competing interests.

\section{Author details}

'Emergency Department, University Medical Center (UMCG), PO Box 30001 9700 RB Groningen, The Netherlands. ${ }^{2}$ Critical Care Department (ICV), University Medical Center (UMCG), PO Box 30001, 9700 RB Groningen, The Netherlands.

Published: 14 March 2012

\section{References}

1. Wilson TJ, Brown DL, Meurer WJ, Stetler WR Jr., Wilkinson DA, Fletcher JJ: Risk factors associated with peripherally inserted central venous catheterrelated large vein thrombosis in neurological intensive care patients. Intensive Care Med 2012, 38:272-278.

2. Pittiruti M, Brutti A, Celentano D, Pomponi M, Biasucci DG, Annetta MG, Scoppettuolo G: Clinical experience with power injectable peripherally inserted central catheters in intensive care patients. Crit Care 2012, 16:R21.
3. Gunst M, Matsushima K, Vanek S, Gunst R, Shafi S, Frankel H: Peripherally inserted central catheters may lower the incidence of catheter-related blood stream infections in patients in surgical intensive care units. Surg Infect (Larchmt) 2011, 12:279-282.

4. Scoppettuolo G, Dolcetti L, Taraschi C, Chiarini C, Donato C, Lardo S, LaGreca A, Pittiruti M: Targeting zero CLABSI in patients with PICC lines implementing a bundle of interventions: a case control study. Abstract presented at the 25th annual scientific meeting of the Association for Vascular Access; 3-6 Oct. 2011; San Jose, CA.

5. Evans RS, Sharp JH, Linford LH, Lloyd JF, Tripp JS, Jones JP, Woller SC, Stevens SM, Elliott CG, Weaver LK: Risk of symptomatic DVT associated with peripherally inserted central catheters. Chest 2010, 138:803-810.

6. Meyer BM: Managing peripherally inserted central catheter thrombosis risk: a guide for clinical best practice. JAVA 2011, 16:144-147.

doi:10.1186/cc11210

Cite this article as: Ligtenberg JJM, et al.: Peripherally inserted central catheters: a walk down memory lane .... Critical Care 2012, 16:418. 